\title{
Functional response of U.S. grasslands to the early 21 st-century drought
}

\author{
M. Susan Moran, ${ }^{1,9}$ Guillermo E. Ponce-Campos, ${ }^{1}$ Alfredo Huete,${ }^{2}$ Mitchel P. McClaran, ${ }^{3}$ \\ Yongguang Zhang, ${ }^{1}$ Erik P. Hamerlynck, ${ }^{1}$ David J. Augustine, ${ }^{4}$ Stacey A. Gunter,${ }^{5}$ Stanley G. Kitchen, ${ }^{6}$ \\ Debra P. C. Peters, ${ }^{7}$ Patrick J. Starks, ${ }^{8}$ and Mariano Hernandez ${ }^{1}$ \\ ${ }^{1}$ USDA Agricultural Research Service, Southwest Watershed Research, Tucson, Arizona 85719 USA \\ ${ }^{2}$ Plant Functional Biology and Climate Change Cluster, University of Technology, Sydney 2007 Australia \\ ${ }^{3}$ School of Natural Resources and the Environment, University of Arizona, Tucson, Arizona 85721 USA \\ ${ }^{4}$ USDA Agricultural Research Service, Rangeland Resources Research Unit, Fort Collins, Colorado 80526 USA \\ ${ }^{5}$ USDA Agricultural Research Service, Southern Plains Range Research Station, Woodward, Oklahoma 73801 USA \\ ${ }^{6}$ USDA Forest Service, Rocky Mountain Research Station, Provo, Utah 84606 USA \\ ${ }^{7}$ USDA Agricultural Research Service, Jornada Experimental Range, Las Cruces, New Mexico 30003 USA \\ ${ }^{8}$ USDA Agricultural Research Service, Grazing Lands Research Laboratory, El Reno, Oklahoma 73036 USA
}

\begin{abstract}
Grasslands across the United States play a key role in regional livelihood and national food security. Yet, it is still unclear how this important resource will respond to the prolonged warm droughts and more intense rainfall events predicted with climate change. The early 21st-century drought in the southwestern United States resulted in hydroclimatic conditions that are similar to those expected with future climate change. We investigated the impact of the early 21st-century drought on aboveground net primary production (ANPP) of six desert and plains grasslands dominated by $\mathrm{C}_{4}$ (warm season) grasses in terms of significant deviations between observed and expected ANPP. In desert grasslands, drought-induced grass mortality led to shifts in the functional response to annual total precipitation $\left(P_{\mathrm{T}}\right)$, and in some cases, new species assemblages occurred that included invasive species. In contrast, the ANPP in plains grasslands exhibited a strong linear function of the current-year $P_{\mathrm{T}}$ and the previous-year ANPP, despite prolonged warm drought. We used these results to disentangle the impacts of interannual total precipitation, intra-annual precipitation patterns, and grassland abundance on ANPP, and thus generalize the functional response of $\mathrm{C}_{4}$ grasslands to predicted climate change. This will allow managers to plan for predictable shifts in resources associated with climate change related to fire risk, loss of forage, and ecosystem services.
\end{abstract}

Key words: climate change; desert; extreme events; grassland production; invasive species; plains; precipitation variability; resilience; warm drought.

\section{INTRODUCTION}

General circulation models predict that climate change will result in an unprecedented concurrence of regional drying and warming (e.g., Seager et al. 2007). Further, droughts induced by climate change are predicted to be spatially expansive and temporally synchronous (Weiss et al. 2009). These droughts are also predicted to include novel precipitation patterns characterized by more intense rainfall events and longer dry interstorm intervals (Easterling et al. 2000, Solomon et al. 2007), potentially inducing dramatic region-wide changes in ecosystem productivity. In the western United States, recent episodes of drought-induced perennial plant mortality in forests (Allen et al. 2010), woodlands (Breshears et al. 2005), shrublands (McAu-

Manuscript received 3 September 2013; revised 2 January 2014; accepted 21 January 2014. Corresponding Editor: A. Classen.

${ }^{9}$ E-mail: susan.moran@ars.usda.gov liffe and Hamerlynck 2010), and grasslands (Scott et al. 2010) have been attributed to warmer prevailing temperatures that exacerbated drought conditions. Such mortality and potential subsequent development of novel species assemblages (Williams and Jackson 2007, Willis and Bhagwat 2009) could have significant implications for the relationship between annual precipitation and ecosystem productivity.

North American grassland ecosystems are expected to be sensitive to global climate change because they have the capacity for large and rapid responses of production to annual precipitation (Sala et al. 2000, Knapp and Smith 2001, Suttle et al. 2007, Reichmann et al. 2013). However, there is uncertainty how grassland production will respond to new hydroclimatic conditions because there is still no consensus on the underlying mechanisms driving these responses even though individual grassland sites have been studied for long-term responses, and these sites have been compared for relative sensitivities (Epstein et al. 2002, Morgan et al. 2011). As a result, there are few generalizations about the regional behav- 
ior of grasslands with prolonged warm drought and more extreme precipitation events (Peters et al. 2004).

Studies of grassland productivity in arid and semiarid ecosystems are generally based on the response of aboveground net primary production (ANPP or total new biomass produced aboveground during a specific interval) to variability in total annual precipitation $\left(P_{\mathrm{T}}\right)$. There is a well-accepted relation in North America between mean annual precipitation (MAP, the longterm average of $P_{\mathrm{T}}$ ) and ANPP across sites from arid to mesic ecosystems, termed the spatial model (Sala et al. 1988b, Knapp and Smith 2001, Huxman et al. 2004), and there is some understanding about how this spatial model will respond to climate change (Sala et al. 2012, Ponce-Campos et al. 2013). However, the cross-site spatial model differs substantially from the within-site temporal model (e.g., Huxman et al. 2004, Sala et al. 2012), and there is no consensus on the biogeochemical, physiological, or community-level mechanisms that may explain this disparity (Lauenroth and Sala 1992, Muldavin et al. 2008). Understanding this distinction is important because it is the temporal model that will be used to manage grassland resources and to plan for shifts in functional processes associated with climate change.

Although there is general agreement that the temporal model is contingent upon the life history of organisms, geography, and limitations of nutrients, light, and water, there is little consensus on the underlying mechanisms driving the regional patterns because most temporal models have been developed for individual sites. Knapp and Smith (2001) reported a temporal model for grasslands where the pulses in ANPP in years of above-average precipitation were larger than declines in ANPP during years with below-average precipitation. They attributed this asymmetry to buffering mechanisms that reduced the impact of drought. Using largely the same data set, Huxman et al. (2004) reported that temporal models for single sites followed a pattern where rainfall use efficiency (RUE is $\mathrm{ANPP} / P_{\mathrm{T}}$ ) increased from high- to low-production biomes because resources other than soil water became limiting in the high-production biomes. With a data set limited to those low-production-high-RUE sites (subhumid grass and shrub-dominated rangelands), Sala et al. (2012) reported that the temporal model was best characterized by the current-year precipitation and the previous-year ANPP because of time lags in response associated with meristem density at the plant scale and grass abundance at the plot scale. Their results suggest that in such rangeland systems, the response of ANPP to long-term drought would increase with time as the lag-effect continued, ultimately leading to functional and structural changes as hypothesized by Smith et al. (2009). Ponce-Campos et al. (2013) suggested that with prolonged warm drought, grassland biomes would reach a maximum RUE, approaching a threshold which, when crossed, would result in biome reorganization. The concurrence of larger storms and longer dry intervals has been reported to decrease ANPP in intermountain desert grasslands (Zhang et al. 2013) and may increase ANPP in Great Plains grasslands (Heisler-White et al. 2009, Cherwin and Knapp 2012).

This ecological complexity has made regional generalizations of temporal models of the ANPP-to- $P_{\mathrm{T}}$ relation difficult. Our objective was to develop a temporal model of the relation between ANPP and $P_{\mathrm{T}}$ for arid and mesic regions of the $\mathrm{C}_{4}$ grasslands of the southwestern United States. Deviations between observed and expected ANPP were used to determine changes in function related to the long-term ANPP-to$P_{\mathrm{T}}$ relation.

We focused on grasslands of the United States for several reasons. First, a basic goal of ours was to provide a climate change context to the temporal model. Recent hydroclimatic conditions in the United States provided an opportunity to study the functional response of biomes dominated by $\mathrm{C}_{4}$ grasses to warm drought and extreme precipitation patterns. In the southwest United States, the early 21 st-century drought has resulted in regional annual precipitation $25 \%$ below 20th-century means and an average annual temperature $0.8^{\circ} \mathrm{C}$ warmer than the 20th-century mean; these conditions are similar to those expected with climate change (MacDonald 2010). Second, the continental United States is characterized by two distinct regions supporting extensive grasslands: the Great Plains and the intermountain desert (hereafter referred to as plains and desert grasslands). This allowed us to investigate the impact of life history on the temporal model related to climate and grazing pressures. Third, our research was intentionally designed to utilize in situ knowledge to understand the mechanics behind site-specific behavior. Within this region, there are six USDA experimental sites with continuous research and data collection over the past 20-100 years. We combined these case studies to understand the mechanisms underlying deviations from predicted ANPP-to- $\mathrm{P}_{\mathrm{T}}$ relations and make regional generalizations that could apply to similar grasslands around the world.

\section{Materials, Methods, And Models}

\section{Study sites}

We focused on six USDA long-term experimental sites during the period from 2000 to 2011 (Fig. 1). These study sites encompass a range of precipitation and temperature regimes and are dominated by $\mathrm{C}_{4}$ grasses (Table 1). Locations include three arid intermountain desert grasslands (mean annual precipitation [MAP] $<350 \mathrm{~mm} / \mathrm{yr}$ ), Desert Experimental Range (DER) in Utah, Jornada Experimental Range (JRN) in New Mexico, and Walnut Gulch Experimental Watershed (WGE) in Arizona; and three mesic Great Plains grasslands (MAP $\geq 350 \mathrm{~mm} / \mathrm{yr}$ ), Central Plains Experimental Range (CPL) in Colorado and Southern Plains Experimental Range (SPL) and Little Washita River 


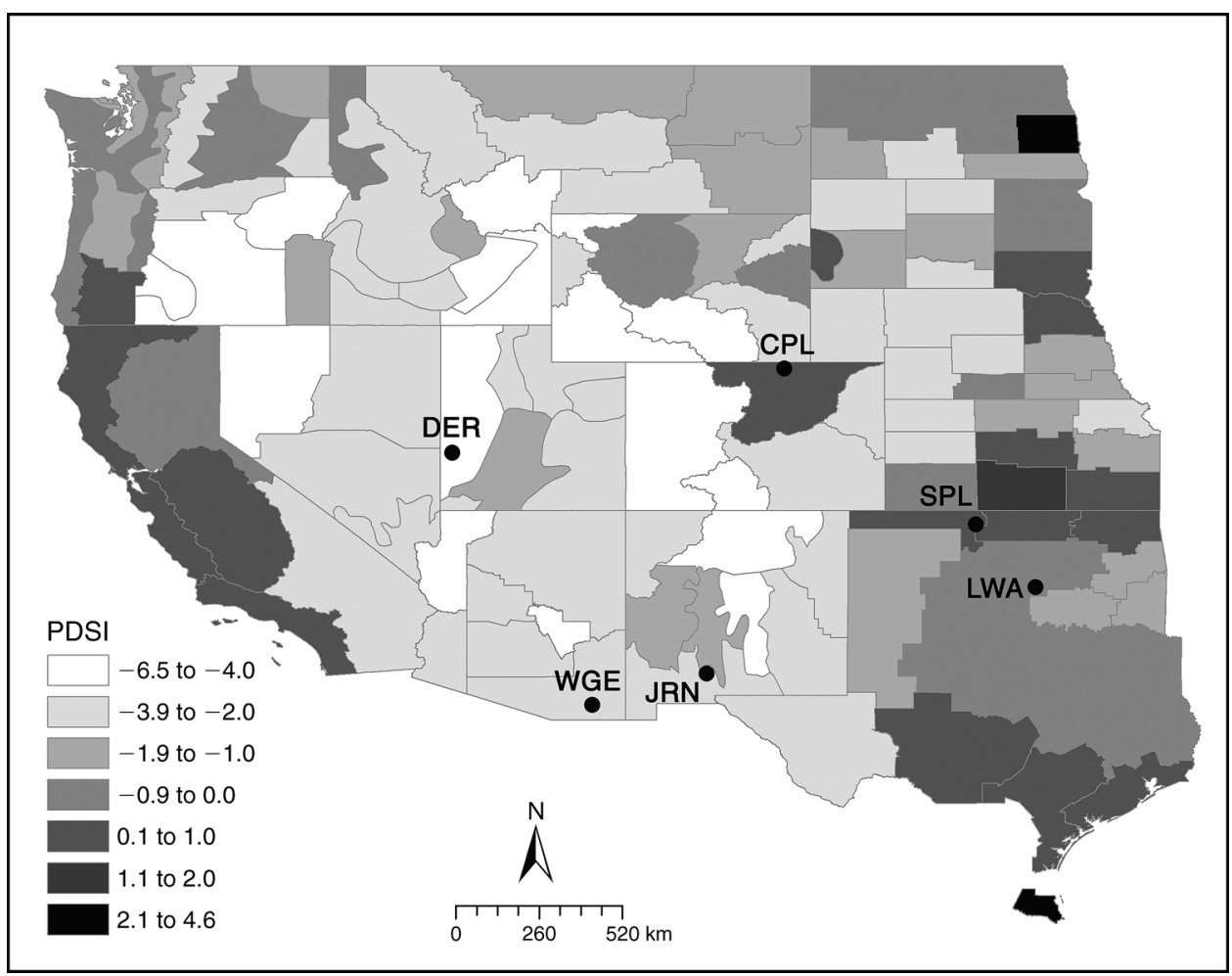

FIG. 1. Locations of the six grassland sites across the southwest United States, overlain on an image of regional Palmer drought severity index (PDSI) over the NOAA/NCDC polygons for year 2003 during the early 21 st-century drought (from http://www7. ncdc.noaa.gov/CDO/cdo). CPL is Central Plains Experimental Range, DER is Desert Experimental Range, SPL is Southern Plains Experimental Range, LWA is Little Washita River Experimental Watershed, JRN is Jornada Experimental Range, and WGE is Walnut Gulch Experimental Watershed.

Experimental Watershed (LWA) in Oklahoma. Sitelevel experts were available at each experimental site to interpret and validate results based on long-term records.

These grassland ecosystems in the continental United States need to be set in context of the historical evolution across North America that has resulted in regional structure and function. North American grasslands occur in transitional climate regions where prolonged dry periods favor perennial grass persistence; thus most plants are tolerant of short-term drought, but the frequency of species with tolerance to severe, long-

TABLE 1. Characteristics of the six grassland sites, including the dominant grasses at the beginning of the decade (year 2000), mean annual sum of precipitation (MAP), and mean annual maximum temperature (MAT) with standard deviations in parentheses.

\begin{tabular}{|c|c|c|c|}
\hline Site name and location & Dominant grasses in year 2000 & MAP (mm) & $\operatorname{MAT}\left({ }^{\circ} \mathrm{C}\right)$ \\
\hline \multicolumn{4}{|l|}{ Intermountain desert grasslands } \\
\hline DER, Desert Experimental Range, Utah & $\begin{array}{l}\mathrm{C}_{4}: \text { Sporobolus cryptandrus } \\
\mathrm{C}_{3}: \text { Oryzopsis hymenoides }\end{array}$ & $179(58)$ & $20(0.8)$ \\
\hline JRN, Jornada Experimental Range, New Mexico & $\begin{array}{l}\mathrm{C}_{4}: \text { Bouteloua eriopoda; } \\
\quad \text { Sporobolus flexuosa }\end{array}$ & $241(73)$ & $25(0.8)$ \\
\hline $\begin{array}{l}\text { WGE, Walnut Gulch Experimental Watershed, } \\
\text { Arizona }\end{array}$ & $\begin{array}{l}\mathrm{C}_{4} \text { : Bouteloua eriopoda; Bouteloua } \\
\text { curtipendula }\end{array}$ & $305(91)$ & $25(0.9)$ \\
\hline \multicolumn{4}{|l|}{ Great Plains grasslands } \\
\hline CPL, Central Plains Experimental Range, Colorado & $\begin{array}{l}\mathrm{C}_{4}: \text { Bouteloua gracilis } \\
\mathrm{C}_{3}: \text { Hesperostipa comata }\end{array}$ & $381(91)$ & $16(1.5)$ \\
\hline $\begin{array}{l}\text { SPL, Southern Plains Experimental Range, } \\
\text { Oklahoma }\end{array}$ & $\begin{array}{l}\mathrm{C}_{4}: \text { Bouteloua curtipendula } \\
\text { Andropogon hallii }\end{array}$ & $587(165)$ & $22(0.9)$ \\
\hline $\begin{array}{l}\text { LWA, Little Washita River Experimental } \\
\text { Watershed, Oklahoma }\end{array}$ & $\begin{array}{l}\mathrm{C}_{4}: \text { Schizachyrium scoparium } \\
\text { Andropogon gerardii }\end{array}$ & $794(197)$ & $24(1.0)$ \\
\hline
\end{tabular}

Note: Averages represent the 32-year period 1980-2011 for all sites except DER (18-year period 1994-2011). All sites are in the United States. 
term drought increases as MAP decreases (McPherson 1997, McCarron and Knapp 2001, Peltzer and Köchy 2001, Briggs et al. 2005). Plains grasslands are dominated by sod-forming bunchgrasses capable of tolerating prehistoric and historic grazing pressure, especially by large ungulates (Collins et al. 1998, Lyman and Wolverton 2002). This region encompasses mesic tallgrass prairie, mixed-grass prairie, and semiarid shortgrass steppe and follows a declining east-west precipitation gradient with similar seasonal rainfall distribution peaking in the summer when temperatures are warmest (Borchert 1950). In contrast, desert grasslands are characterized by widely spaced, drought-tolerant bunchgrasses, and the region did not historically support high densities of large ungulate populations (McClaran 1997, Lyman and Wolverton 2002). These arid grasslands experience lower, more variable interannual rainfall, with distinct summer and winter peaks that reflect the relative strengths of North American monsoon and frontal systems influenced by El Niño Southern Oscillation (ENSO) and Northern Annular Mode dynamics (Sheppard et al. 2002, McAfee and Russell 2008).

\section{Meteorological data}

Long-term in situ meteorological measurements were used to derive climatic variables to characterize the hydroclimatic conditions. The $P_{\mathrm{T}}$ was computed as a sum of daily precipitation based on the water year (1 October-30 September). The Palmer drought severity index (PDSI) was computed from measurements of monthly precipitation and temperature from 1960 to 2011, where negative and positive values indicated dry and wet conditions, respectively (Dai 2011). For the DER site in Utah, the record of continuous in situ meteorological measurements was only available from 1994 to present, and consequently, PDSI was computed using extended records at nearby NOAA stations.

National networks with instrumentation near the study sites provided additional information. The NOAA National Climate Data Center (NCDC) provided regional annual PDSI values from 1900 to present based on measurements that included monthly precipitation and average air temperature and estimates of local soil available water content. These data were used to compare the 1930s dust bowl drought, the 1950s drought that affected much of the southwest and southern Great Plains of the United Staes, and the contemporary early 21 st-century drought.

We defined a hydroclimatic index based on PDSI to be used as a predictor of ecosystem functional response to drought based on findings that the number of consecutive months of drought extending over multiyear periods was a good predictor of plant mortality (McAuliffe and Hamerlynck 2010). Since monthly PDSI was computed based on conditions during the prior 12 months, we considered the PDSI in September (PDSI ${ }_{\text {Sep }}$ ) to be an indicator of the consecutive months of drought weighted more heavily on the growing season of that water year. The distribution of $\mathrm{PDSI}_{\text {Sep }}$ during the late 20th century (1980-1999) was used to determine the values associated with an extreme wet year (in top fifth percentile), a wet year (in top 20th percentile), a warm drought year (in bottom 20th percentile), and an extreme drought year (in bottom fifth percentile). That is, the bottom fifth percentile translates to the driest year in the 20-year record (1980-1999), and similarly, the bottom 20th percentile translates roughly to the fourth driest year.

To characterize the seasonal precipitation pattern, we used an R95 index that was proposed by Frich et al. (2002) and has been adopted as a standard output in the Intergovernmental Panel on Climate Change (IPCC) AR2 (second assessment report; Solomon et al. 2007). R95 is the annual precipitation amount due to daily precipitation exceeding the 95th percentile of the full temporal record (1970-2011). To make this value comparable across sites along a precipitation gradient, we normalized R95 by $P_{\mathrm{T}}$ to derive R95\%. The index R95\% is the fraction of $P_{\mathrm{T}}$ due to the events above the 95th percentile and provides a standardized annual index of the frequency of large storms.

\section{Aboveground net primary production (ANPP)}

Many studies of cross-site ecosystem production are based on a compilation of in situ measurements of ANPP from long-term experimental sites across the United States and around the world. This approach can lead to some uncertainty because procedures are not consistent across sites, and in some cases, not consistent over time at a given site (Sala et al. 1988a, Biondini et al. 1991). Further, the general approach for estimating ANPP for grasslands is to schedule the destructive sample for dates associated with peak biomass.

Instead, we used satellite observations of the enhanced vegetation index (EVI) from NASA's moderateresolution imaging spectroradiometer (MODIS) as a surrogate for annual ANPP. At each location, a site of $\sim 3 \times 3 \mathrm{~km}$ was chosen where vegetation was dominated by $\mathrm{C}_{4}$ grasses and in situ meteorological records representative of the location could be obtained. MODIS EVI data were extracted for this location, where

$$
\mathrm{EVI}=G \frac{\rho_{\mathrm{NIR}}-\rho_{\text {red }}}{\rho_{\mathrm{NIR}}+C_{1} \rho_{\text {red }}-C_{2} \rho_{\text {blue }}+L}
$$

and $\rho_{\text {NIR }}, \rho_{\text {red }}$, and $\rho_{\text {blue }}$ are atmospherically corrected surface near-infrared, red, and blue reflectance bands, respectively; $G$ is a gain factor; $C_{1}$ and $C_{2}$ are the coefficients of the aerosol resistance term; and $L$ functions as the soil-adjustment factor (Huete et al. 2002). Values of EVI were averaged over an area of 2.25 $\times 2.25 \mathrm{~km}(9 \times 9$ MODIS pixels $)$ extracted from each MODIS scene $(23$ per year $\times 10$ years $=230$ scenes $)$ representing the dominant vegetation type at the site. Using the software TimeSat (Jönsson and Eklundh 

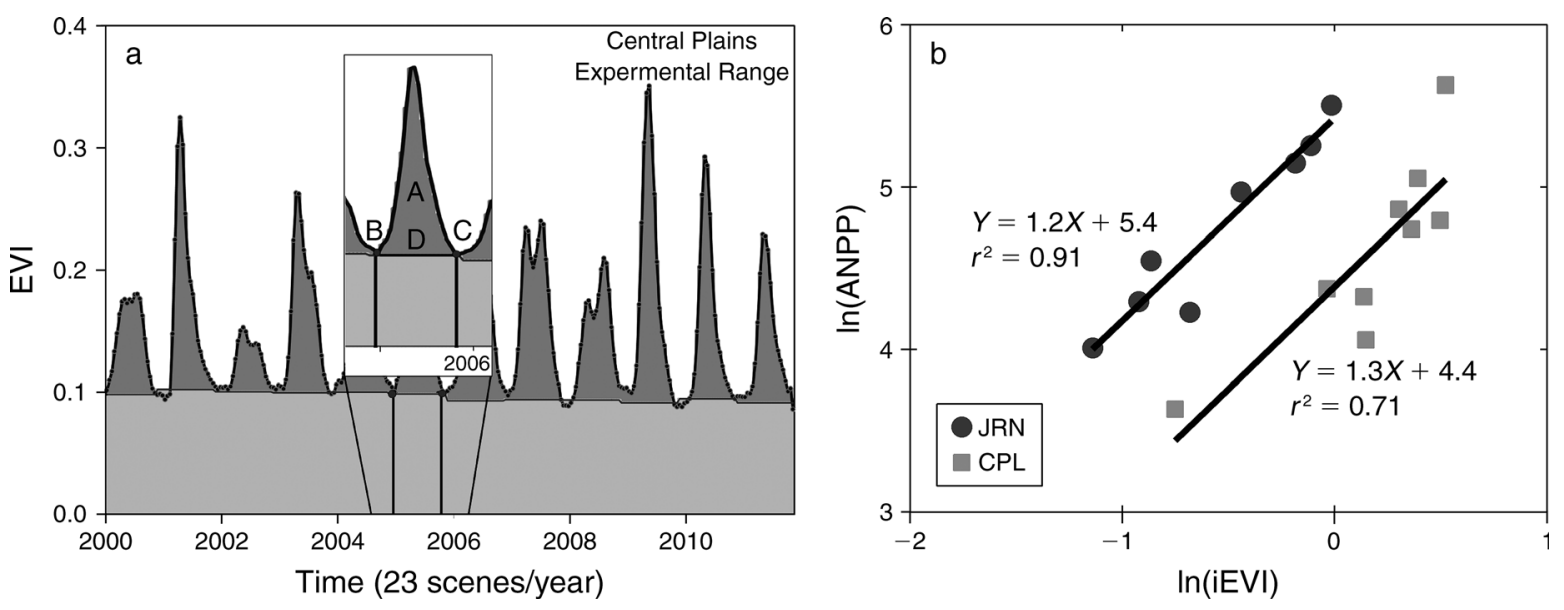

FIG. 2. NASA's MODIS enhanced vegetation index (EVI). (a) An example of the time series of integrated EVI (iEVI) for Central Plains Experimental Range (CPL), where (A) the iEVI is the integral of the difference between the function describing the season and (D) the base level from (B) season start to (C) season end. (b) The log-log relation (black lines) between the iEVI and aboveground net primary production (ANPP) measured in situ at Jornada Experimental Range (JRN; 2000-2008) and CPL (20002009), respectively.

2004), we applied pixel-based quality control to remove noise from the time series and smoothed the time series to integrate the EVI over the active growing season (A in Fig. 2a; hereafter referred to as the integrated EVI or iEVI).

The MODIS iEVI has been used to quantify the dynamics of ANPP across biomes ranging from arid grassland to forest (Ponce-Campos et al. 2013, Zhang et al. 2013). For this study, plot-scale measurements of ANPP at JRN and CPL sites during the 2000-2011 study period (Morgan et al. 2011, Peters et al. 2012) were compared with iEVI measurements. Though there are scale differences between measurements of iEVI and ANPP (i.e., ANPP measurements are commonly made at scales from $1 \mathrm{~m}^{2}$ to $0.01 \mathrm{~km}^{2}$ vs. iEVI at $\sim 2 \times 2 \mathrm{~km}$ ), ground-based measures of ANPP were significantly related to $\mathrm{iEVI}$ for these select grasslands over the time period $2000-2011$ in a $\log -\log$ relation $\left(r^{2}=0.71\right.$ and $0.91, P<0.01$; Fig. 2b). The log-log relation accounted for the uneven distribution of ANPP estimates over time.

A simple test was conducted to compare in situ ANPP estimates made near the peak of the growing season to iEVI values integrated over the entire growing season. At CPL, it is the protocol to make ANPP destructive samples in the first week of August. We integrated the EVI from the beginning of the growing season to the first week in August (rather than the full water year) to be comparable to the time of the CPL estimate. The log$\log$ relation improved from $r^{2}=0.71$ (Fig. 2b) to $r^{2}=$ 0.82 with this synchronization of time periods. This result implies that the iEVI may provide more temporal stability, and less uncertainty, than in situ estimates of annual ANPP associated with destructive samples scheduled to coincide with the elusive date of peak greenness. Thus, we assumed that the iEVI was a reasonable surrogate for ANPP interannual variability at all six sites in our analyses, and the terms iEVI and ANPP are used interchangeably in further discussion.

Standardized values of $P_{\mathrm{T}}$ and iEVI were computed for intersite comparison $\left(P_{\mathrm{TS}}\right.$ and $\left.\mathrm{iEVI}_{\mathrm{S}}\right)$, as the deviation of the $i$-year value from the 11-year average in units of standard deviation $(\sigma)$, i.e.,

$$
P_{\mathrm{TS}}=\left(P_{\mathrm{Ti}}-\overline{P_{\mathrm{T}}}\right) / \sigma_{\mathrm{P}_{\mathrm{T}}}
$$

and

$$
\mathrm{iEVI}_{\mathrm{S}}=\left(\mathrm{iEVI} \mathrm{i}_{\mathrm{i}}-\overline{\mathrm{iEVI}}\right) / \sigma_{\mathrm{iEVI}}
$$

Differences greater than $1 \sigma$ between $\mathrm{iEVI}_{\mathrm{S}}$ and $P_{\mathrm{TS}}$ for any given year indicated an anomaly in the functional response of the grassland production to precipitation and a potential indication of impact of the warm drought conditions in the early 21 st century.

\section{Temporal model}

Most of the previous studies have focused on the spatial model of ANPP and $P_{\mathrm{T}}$ for MAP ranging from $\sim 100$ to $\sim 3000 \mathrm{~mm} / \mathrm{yr}$. This is summarized here and interpreted for application to a temporal model for grasslands. There is general agreement that the spatial model of ANPP and $P_{\mathrm{T}}$ is exponential, with a form $\mathrm{ANPP}=b_{0}\left(1-e^{b_{1} P_{\mathrm{T}}}\right)$ (Huxman et al. 2004, PonceCampos et al. 2013). Zhang et al. (2013) proposed a multiple nonlinear regression model to account for the significant effects of extreme precipitation patterns, where $\mathrm{iEVI}=\left(b_{0}+b_{1} \mathrm{R} 95 \%\right)\left(1-e^{b_{2} P_{\mathrm{T}}}\right)$. They found that $\mathrm{R} 95 \%$ and $P_{\mathrm{T}}$ together explained $88 \%$ of the variance in observed ANPP across biomes from desert grassland to temperate forest. The temporal model for grassland sites with MAP $<1000 \mathrm{~mm}$ has been approximated with a linear fit, where ANPP $=b_{0}+$ $b_{1} P_{\mathrm{T}}$ (e.g., Briggs and Knapp 1995). For arid to 
subhumid grass- or shrub-dominant systems (i.e., rangelands), Sala et al. (2012) suggested that ANPP was best characterized by the current-year precipitation $\left(P_{\mathrm{T}(t)}\right.$, where $t$ is the current year) and the previous-year $\operatorname{ANPP}\left(\operatorname{ANPP}_{(t-1)}\right)$, where ANPP $=b_{0}+b_{1} P_{\mathrm{T}(t)}+$ $b_{2} \operatorname{ANPP}_{(t-1)}$. Though no correlation coefficient was provided for this unified model, the logic that previousyear ANPP controls a significant fraction of currentyear production was discussed in Introduction.

An equivalent set of relations specific to this study of six grassland sites was derived by (1) substituting the linear temporal ANPP-to- $P_{\mathrm{T}}$ relation in place of the exponential spatial relation and (2) using $\mathrm{iEVI}_{\mathrm{S}}$ as a proxy for ANPP. As a result

$$
\mathrm{iEVI}_{\mathrm{S}}=b_{0}+b_{1} P_{\mathrm{TS}(t)}
$$

from Briggs and Knapp (1995);

$$
\mathrm{iEVI}_{\mathrm{S}}=b_{0}+b_{1} P_{\mathrm{TS}(t)}+b_{2} \mathrm{iEVI}_{\mathrm{S}(t-1)}
$$

from Sala et al. (2012); and

$$
\mathrm{iEVI}_{\mathrm{S}}=b_{0}+b_{1} P_{\mathrm{TS}(t)}+b_{2} \mathrm{R} 95 \%
$$

from Zhang et al. (2013).

Combining these relations, it is reasonable to propose that

$$
\mathrm{iEVI}_{\mathrm{S}}=b_{0}+b_{1} P_{\mathrm{TS}(t)}+b_{2} \mathrm{iEVI}_{\mathrm{S}(t-1)} b_{3} \mathrm{R} 95 \% .
$$

We fit models for all possible combinations of predictors (Eqs. 3-6) to data for the three combined desert grassland sites and to data for the three combined plains grassland sites. This provided the expected response of $\mathrm{iEVI}_{\mathrm{S}}$ to model parameters for detection of significant deviations between observed and expected ANPP. We assessed models based on Akaike's information criterion adjusted for small sample sizes $\left(\mathrm{AIC}_{\mathrm{c}}\right)$ to evaluate the benefit of increasing model complexity from Eq. 3 to Eq. 6 (Burnham and Anderson 2002). We selected models of greater complexity than Eq. 3 when the inclusion of an additional model parameter reduced AIC by more than 2.0 (Burnham and Anderson 2002). We also report regression correlation coefficients $\left(r^{2}\right)$ as an absolute measure of model fit. We note that intercepts for all models were close to zero such that including intercepts did not produce more parsimonious models $(\triangle \mathrm{AIC}<2$ for models with vs. without intercepts in all cases); hence, intercepts were not included in the models.

\section{RESULTS}

\section{Characteristics of the early 21st-century drought}

During the early 21 st century, these six grasslands experienced prolonged drought with warm season temperatures higher than any period in the 20th century, representing new hydroclimatic conditions (Fig. 3). Low precipitation during the early 21 st-century drought was comparable to that during the 1930s dust bowl drought. However, temperature deviations from the historic mean during the early 21 st-century drought were nearly double those reported for the 1930s drought, rising from $0.2^{\circ}$ to $0.8^{\circ} \mathrm{C}$ during the cold season and from $0.6^{\circ}$ to $1.1^{\circ} \mathrm{C}$ during the warm season. The decrease in precipitation in the 1950 s drought was greater than the decrease in the 1930 s and early 21 st-century droughts, but the temperature during the warm season was only $0.6^{\circ} \mathrm{C}$ above the historic mean.

During the early 21st-century drought, the three desert grasslands (DER, JRN, and WGE) and two of the three plains grasslands (CPL and LWA) recorded warm drought periods ranging from five to eight years, and all sites recorded two or more consecutive warm drought years (Fig. 4). All sites recorded at least one extreme warm drought year, and CPL recorded six consecutive extreme warm drought years, where extreme warm drought years were within the bottom fifth percentile and thus drier than the driest year between 1980-1999. For all sites, there were only three years (i.e.,

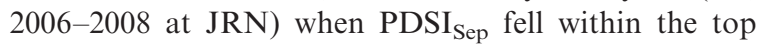
20th percentile and one year when PDSI $_{\text {Sep }}$ fell within the top fifth percentile of the 1980-1999 distribution (i.e., 2011 at DER). Warm season temperatures during the most extreme drought years exceeded the 12-year (2000-2011) average by values ranging from $0.4^{\circ}$ to $1.7^{\circ} \mathrm{C}$ for the desert grasslands and $1.3^{\circ}$ to $2.5^{\circ} \mathrm{C}$ for the plains grasslands.

The R95\% was used as an index of the number of large storms in each year standardized to the long-term average for each site, respectively. We used the Hartigan's dip statistic (HDS) to detect the presence of bimodality in the data, and this yielded the mean and standard deviation of each distribution (Fig. 5). There was a shift in the peaks of this mixed-density function toward larger storms (higher R95\%) in the 2001-2011 time period, determined with one-way analysis of variance. The mean of the leftmost distribution shifted from 8.6 to 13.1 for the periods 1970-1999 and 2001-2011, respectively; and similarly, the mean of the rightmost distribution shifted from 26.3 to $29.1(P<0.05)$.

\section{A temporal model for $C_{4}$ grasslands during altered hydroclimatic conditions}

For desert grasslands, the model based on $P_{\mathrm{TS}(t)}$ alone $(\mathrm{AIC}=67.1)$ explained $60 \%$ of the variance in iEVIs. More complex models that included $\mathrm{iEVI}_{\mathrm{S}(t-1)}$ and $\mathrm{R} 95 \%(\mathrm{AIC}=73.1)$ or $\mathrm{R} 95 \%$ alone $(\mathrm{AIC}=74.8)$ were considerably less parsimonious $(\triangle \mathrm{AIC}=7.3$ and 9.0 ; Table 2). A model that included $\mathrm{iEVI}_{\mathrm{S}(t-1)}$ plus $P_{\mathrm{TS}(t)}$ reduced AIC by 1.3 relative to the $P_{\mathrm{TS}(t)}$ model. Because the small increase in AIC $(\triangle \mathrm{AIC}<2)$ came at the cost of an additional model parameter, we rejected this model and retained the simplest model that predicted $\mathrm{iEVI}_{\mathrm{S}}$ only on the basis of $P_{\mathrm{TS}(t)}$ (Table 2), where

$$
\mathrm{iEVI}_{\mathrm{S}}(\text { Desert })=0.7772\left(P_{\mathrm{TS}(t)}\right) \text {. }
$$

For plains grasslands, the model based on $P_{\mathrm{TS}(t)}$ alone $(\mathrm{AIC}=50.0)$ explained $75 \%$ of the variance in $\mathrm{iEVI}_{\mathrm{S}} . \mathrm{A}$ 


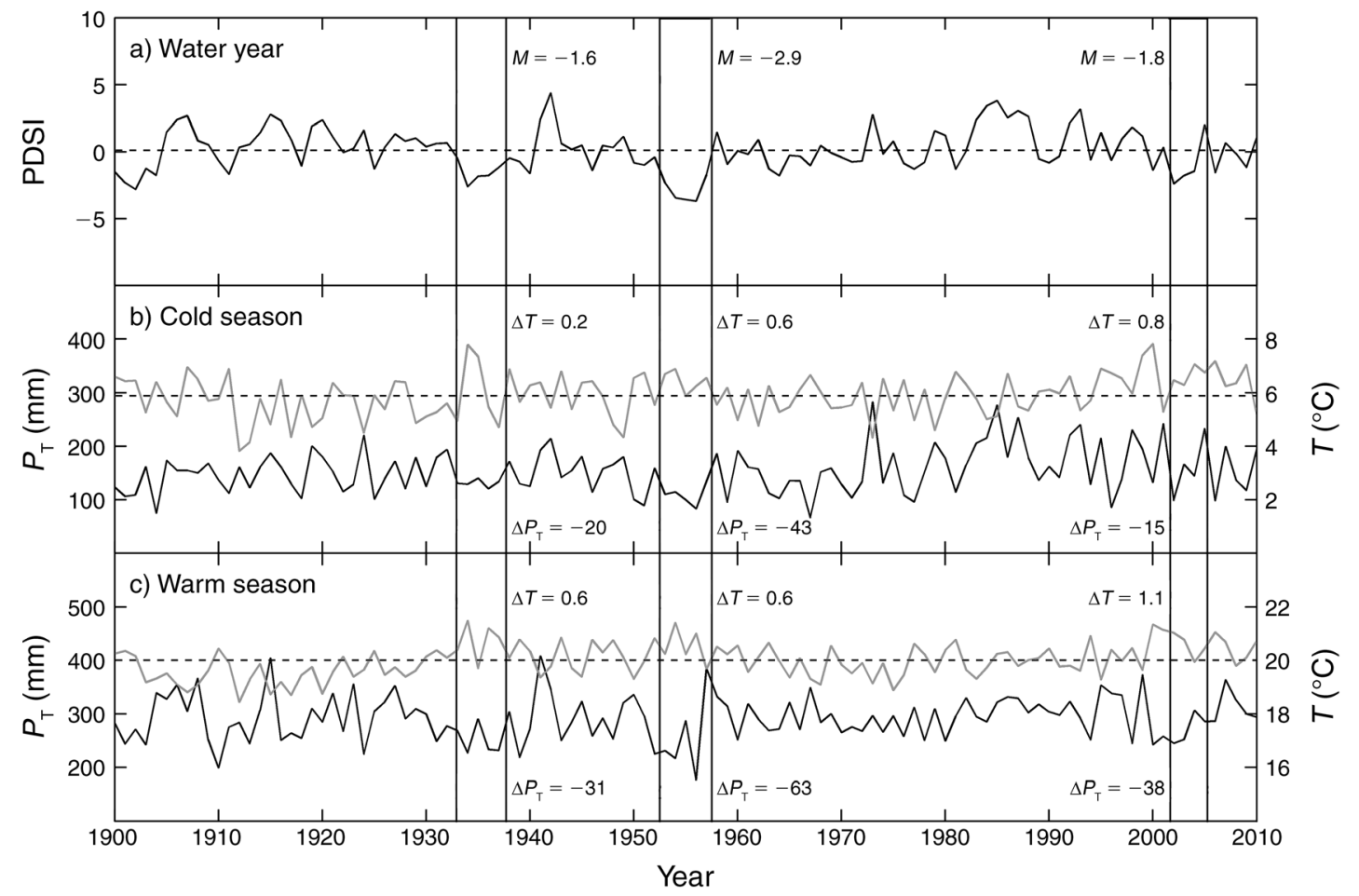

FIG. 3. Palmer drought severity index (PDSI), total precipitation $\left(P_{\mathrm{T}}\right)$, and temperature $(T)$. (a) Annual PDSI (solid line) and (b and c) total seasonal precipitation (lower black solid line) and mean seasonal temperature (upper gray solid line) for the cold season (October to March) and warm season (April to September) averaged over the NOAA National Climate Data Center polygons (Fig. 1) containing the six grassland sites for years 1900-2010 (data from http://www7.ncdc.noaa.gov/CDO/cdo). Dashed lines represent (a) PDSI $=0$ and (b and c) the 1900-2010 mean temperatures. During the three drought periods (boxed), (a) the $M$ values represent the mean PDSI and (b and c) the $\Delta T$ and $\Delta P_{\mathrm{T}}$ values represent the increase in temperature and decrease in precipitation (respectively) from the 1900-2010 mean.

model including both $P_{\mathrm{TS}(t)}$ and $\mathrm{iEVI}_{\mathrm{S}(t-1)}$ was more parsimonious $(\triangle \mathrm{AIC}=-3.7)$ and explained $79 \%$ of the variance in $\mathrm{iEVI}_{\mathrm{S}}$. The selected model was

$$
\operatorname{iEVI}_{\mathrm{S}}(\text { Plains })=0.8811\left(P_{\mathrm{TS}(t)}\right)-0.1522\left(\operatorname{iEVI}_{\mathrm{S}(t-1)}\right) \text {. }
$$

Models including R95\% were considerably less parsimonious $(\triangle \mathrm{AIC}>8.6)$. The intra-annual precipitation pattern (larger storms and longer interstorm dry periods) had only a secondary impact on ANPP and that impact was greater for desert than for plains grasslands (Table 2; and Zhang et al. 2013). To achieve model parsimony, that is, the desire to explain phenomena using fewer parameters, models including R95\% were not considered for these grasslands despite potential improvements in explaining $\mathrm{iEVI}_{\mathrm{S}}$ variance.

\section{Functional response of U.S. grasslands to the early 21st- century drought}

The residuals of the selected models (Eqs.7 and 8) were symmetric across the precipitation gradient (Fig. 6); however, the most striking pattern in the residuals is related to the outliers. After three to four nearconsecutive years of warm drought, residuals for desert grasslands (DER, JRN, and WGE) were greater than $1 \sigma$ or less than $-1 \sigma$. Whereas, the $\mathrm{iEVI}_{\mathrm{S}}$ for plains grasslands (CPL, SPL, and LWA) corresponded well with modeled values for most years (within $\pm 1 \sigma$ ) and did not exhibit the dramatic anomalies observed for desert grasslands. Thus, the root mean squared error (RMSE) of the difference between measured and modeled $\mathrm{iEVI}_{\mathrm{S}}$ was lower for plains grasslands than for desert grasslands (0.46 and 0.6 , respectively).

Of the three outliers in the $i E V I_{S} / P_{T S}$ relationship for desert grasslands, two were associated with plant mortality during prolonged drought, and one involved a lag in the response of ANPP to $P_{\mathrm{T}}$ associated with changes in species dominance (Fig. 7; Table 3). After three near-consecutive years of warm drought (20022003 and 2005), the native grasses at WGE experienced near $100 \%$ mortality (Scott et al. 2010). In 2006, WGE was dominated by opportunistic forbs with ANPP greater than expected if produced by native grasses $\left(\mathrm{iEVI}_{\mathrm{S}}>1 \sigma\right)$. This was concurrent with the spread of the exotic South African grass Eragrostis lehmanniana (Lehmann lovegrass), which then attained dominance by 2007 . This near $100 \%$ mortality of native grasses and replacement with forbs and invasive perennial grass was associated with extreme warm drought (Fig. 

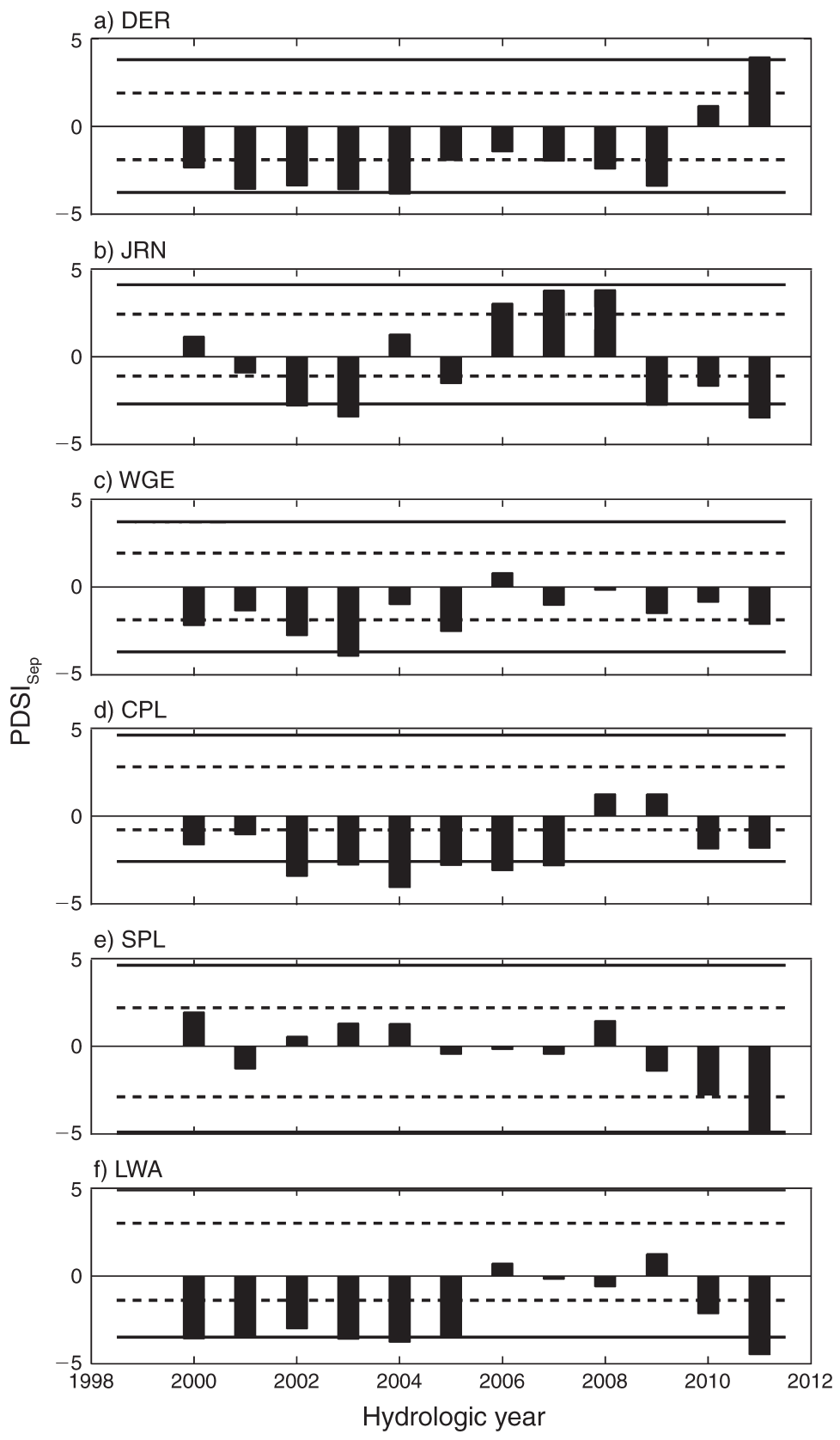

FIG. 4. PDSI in September $\left(\right.$ PDSI $\left._{S e p}\right)$ computed from meteorological measurements at (or near) each site. Lines represent thresholds related to the top and bottom 20th percentiles (dashed lines) and top and bottom fifth percentiles (solid lines) of the PDSI $_{\text {Sep }}$ distribution during the late 20th century (1980-1999). Location site abbreviations are defined in Fig. 1.

7c). Similarly, the unexpectedly high $\mathrm{iEVI}_{\mathrm{S}}$ relative to $P_{\text {TS }}$ at DER in 2010 was associated with an increase in the introduced annual weed Salsola sp. (Russian thistle) documented during ANPP measurements (Fig. 7a). After two consecutive years of extreme warm drought at JRN (2002-2003), ANPP decreased in 2004 by $70 \%$ of the predrought mean despite greater than average precipitation (Peters et al. 2012), followed by an increase in the production of annuals (2005 and 2006) and an increase in the production of the dominant native grasses by 2008. A similar lag in the response of ANPP to $P_{\mathrm{T}}$ was observed at DER in the postdrought years 2005-2006 after five consecutive years of warm drought (Fig. 7a and 7b). No lags nor new species assemblages were observed in plains grasslands over the study period (Table 3 ). Though CPL and LWA sites experienced similarly prolonged warm drought, the ANPP remained primarily responsive to $P_{\mathrm{T}}$ (Fig. $7 \mathrm{~d}$ and $7 \mathrm{f}$ ) and secondarily to previous year ANPP (Eq. 8). 


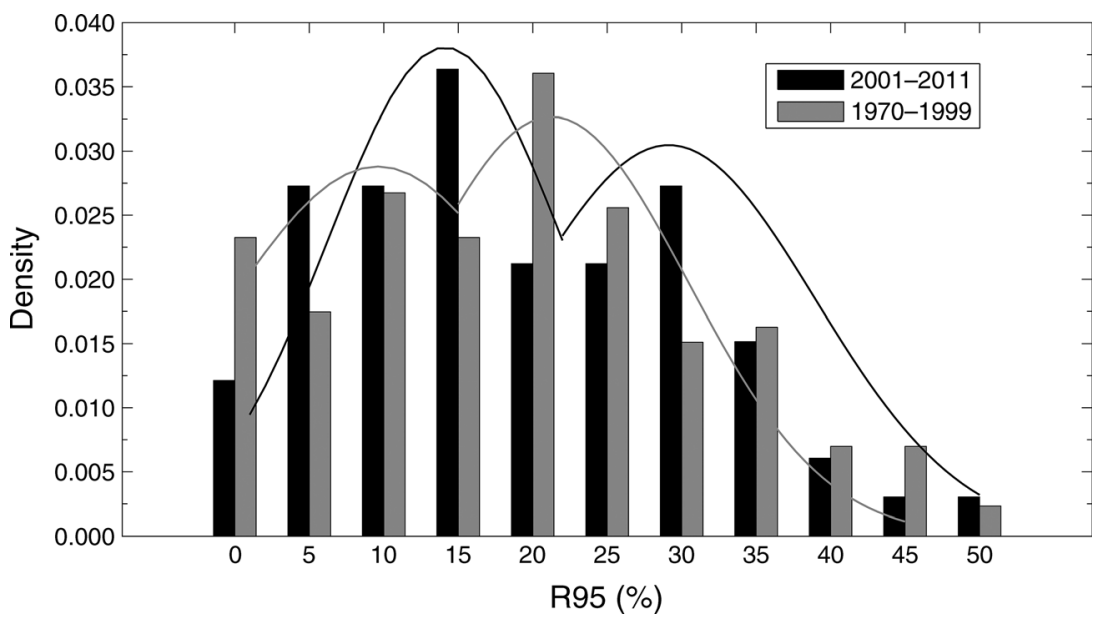

FIG. 5. Frequency distribution of R95\% for two times periods, 1979-1999 and 2001-2011, overlain with the respective density functions based on a mixture of two normal distributions with differing means and variances, illustrating the shift in the peaks of this mixed-density function toward larger storms (higher R95\%) in the 2001-2011 time period. R95 is the annual precipitation amount due to daily precipitation exceeding the 95th percentile of the full temporal record (1970-2011). To make this value comparable across sites along a precipitation gradient, we normalized R95 by $P_{\mathrm{T}}$ to derive R95\%. The index R95\% is the fraction of $P_{\mathrm{T}}$ due to the events above the 95th percentile and provides a standardized annual index of the frequency of large storms.

\section{DISCUSSION}

Results illustrated the regional variation and complex functional response of grassland production to extreme conditions that are analogous to predicted climate change and the importance of multisite experiments for making generalizations. After only a few years of warm drought, desert grasslands entered a long recovery period that shifted the expected ANPP response to $P_{\mathrm{T}}$ for several years, and in some cases, resulted in changed community composition. Though grasses in these arid regions are well adapted to persist through typical seasonal dry periods and episodic, chronic drought (McClaran 1997), this series of warm drought years disrupted the typical productivity response to $P_{\mathrm{T}}$. Plains grasslands exposed to prolonged warm drought responded strongly to both wet and drought conditions (Fig. 6b), a dynamic that confirms the linear temporal model. This led to linear models (Eqs. 7 and 8) across all sites and years that improved the prediction of ANPP, with anomalies attributed to changes in dominant species and lags in the response of ANPP to $P_{\mathrm{T}}$ in desert grasslands (Fig. 7; Table 3).

This was a first attempt to model the response of ANPP to the interdependent factors of current-year precipitation, intra-annual rainfall distribution, and previous-year ANPP in a natural setting. We confirmed that ANPP responded primarily to current-year precipitation in both desert and plains grasslands, and to previous-year ANPP only in the mesic plains grassland. When all factors covaried, the impact of larger storms on grassland ANPP was minimized, in contrast to studies that reported a significant impact of larger storms and longer dry periods on grassland ANPP when precipitation amount was held constant in a manipulated experiment (e.g., Heisler-White et al. 2009) or when effects of precipitation patterns were isolated from effects of $P_{\mathrm{T}}$ (e.g., Zhang et al. 2013). Interestingly, the influence of previous-year ANPP in mesic plains grasslands did not lead to the type of anomalous ANPP-to- $P_{\mathrm{T}}$ relationship that might be expected with chronic drought (Smith et al. 2009). Instead, the anomalous behavior associated with lags, mortality, and new species assemblages was limited to prolonged droughts in the arid desert grasslands, where previous-

TABLE 2. Comparison of models predicting current-year ANPP (integrated standardized enhanced vegetation index, $\mathrm{iEVI}_{\mathrm{S}}$ ) as a function of standardized current-year $t$ precipitation $\left(P_{\mathrm{TS}(t)}\right)$, standardized previous-year ANPP $\left(\mathrm{iEVI}_{\mathrm{S}(t-1)}\right)$, and/or an index of large precipitation events (R95\%).

\begin{tabular}{|c|c|c|c|}
\hline Model & AIC & $\Delta \mathrm{AIC}$ & $r^{2}$ \\
\hline \multicolumn{4}{|l|}{ Desert grasslands } \\
\hline $\begin{array}{l}\boldsymbol{P}_{\mathrm{TS}(t)} \\
P_{\mathrm{TS}(t)}, \mathrm{iEVI}_{\mathrm{S}(t-1)} \\
P_{\mathrm{TS}(t)}, \mathrm{R} \% 5 \% \\
P_{\mathrm{TS}(t)}, \mathrm{iEVI}_{\mathrm{S}(t-1)}, \mathrm{R} 95 \%\end{array}$ & $\begin{array}{l}\mathbf{6 4 . 5} \\
63.4 \\
73.5 \\
72\end{array}$ & $\begin{array}{r}\mathbf{1 . 1} \\
0.0 \\
10.1 \\
8.6\end{array}$ & $\begin{array}{l}\mathbf{0 . 6 0} \\
0.56 \\
0.61 \\
0.57\end{array}$ \\
\hline \multicolumn{4}{|l|}{ Plains grasslands } \\
\hline $\begin{array}{l}P_{\mathrm{TS}(t)} \\
\boldsymbol{P}_{\mathrm{TS}(t)}, \mathbf{i E V I}_{\mathbf{S}(t-1)} \\
P_{\mathrm{TS}(t)}, \mathrm{R} 9 \% \\
P_{\mathrm{TS}(t)}, \mathrm{iEVI}_{\mathrm{S}(t-1)}, \mathrm{R} 95 \%\end{array}$ & $\begin{array}{l}50.0 \\
\mathbf{4 6 . 3} \\
58.9 \\
55.6\end{array}$ & $\begin{array}{r}3.7 \\
\mathbf{0 . 0} \\
12.6 \\
9.3\end{array}$ & $\begin{array}{l}0.75 \\
\mathbf{0 . 7 9} \\
0.75 \\
0.83\end{array}$ \\
\hline
\end{tabular}

Notes: Selected models are shown in boldface. AIC is Akaike's information criterion. Where $\triangle \mathrm{AIC}$ values for two competing models differed by less than 2 , we selected the model with the fewest parameters. R95 is the annual precipitation amount due to daily precipitation exceeding the 95 th percentile of the full temporal record (1970-2011). To make this value comparable across sites along a precipitation gradient, we normalized R95 by $P_{\mathrm{T}}$ to derive R95\%. The index R95\% is the fraction of $P_{\mathrm{T}}$ due to the events above the 95th percentile and provides a standardized annual index of the frequency of large storms. 
a) Desert

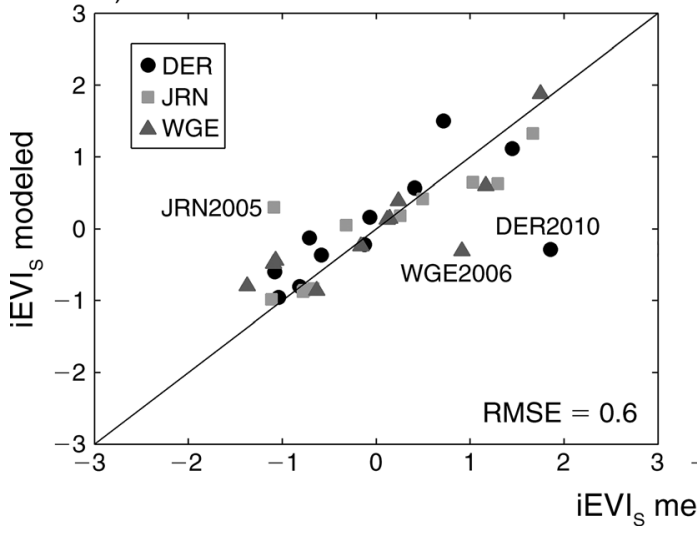

b) Plains

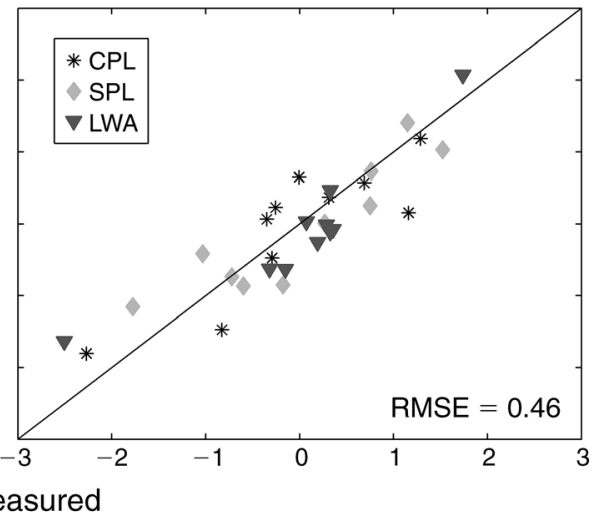

FIG. 6. Relation between measured and modeled standardized integrated enhanced vegetation index (iEVIS) based on Eqs. 7 and 8 for desert (DER, JRN, and WGE; mean annual precipitation [MAP] $<350 \mathrm{~mm} / \mathrm{yr}$ ) and plains (CPL, SPL, and LWA; MAP $\geq 350 \mathrm{~mm} / \mathrm{yr}$ ) grasslands, respectively. Sites and years for which the difference between measured and modeled iEVI $\mathrm{I}_{\mathrm{S}}$ exceeded $\pm 1 \sigma$ $\left( \pm 1\right.$ SD) are labeled. RMSE is the root mean squared error of the difference between measured and modeled iEVI $\mathrm{I}_{\mathrm{S}}$ and standardized total precipitation, $P_{\mathrm{TS}}$. Location site abbreviations are defined in Fig. 1.
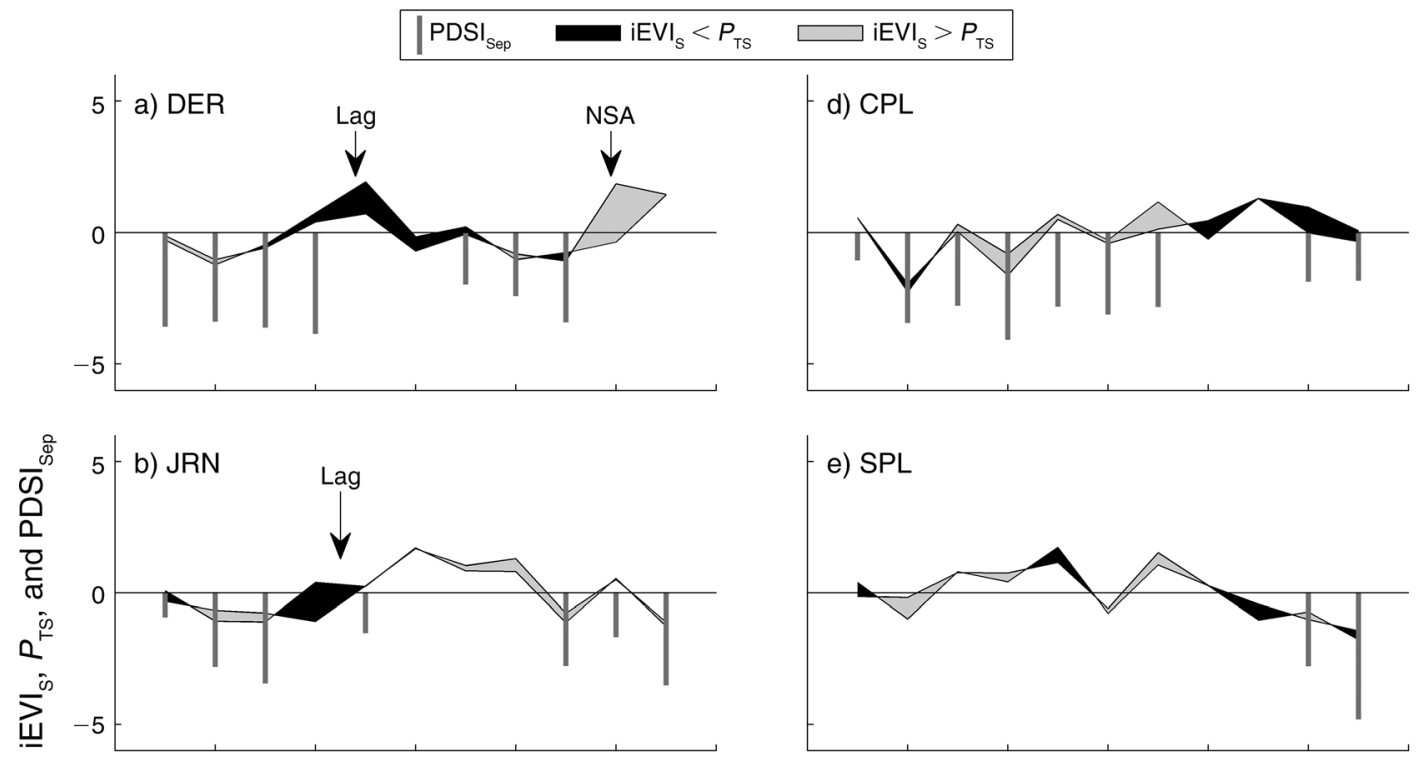

e) SPL
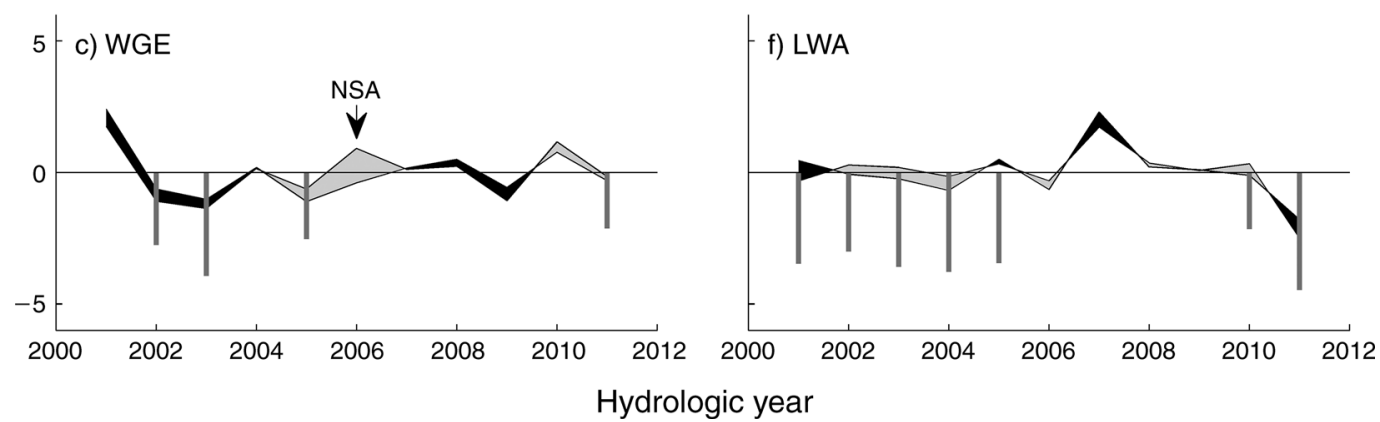

FIG. 7. Trends in standardized iEVI and $P_{\mathrm{T}}\left(\mathrm{iEVI} \mathrm{I}_{\mathrm{S}}\right.$ and $P_{\mathrm{TS}}$, respectively) for each grassland site. Black lines represent iEVI $<$ $P_{\text {TS }}$ (ANPP is lower than expected for the given precipitation, see anomalous negative residuals in Fig. 6), and gray lines represent $\mathrm{iEVI}_{\mathrm{S}}>P_{\mathrm{TS}}$ (ANPP is higher than expected for the given precipitation, see anomalous positive residuals in Fig. 6). The thicker

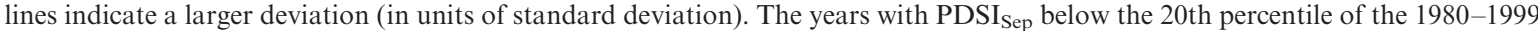
distribution (from Fig. 4) are represented by dark gray vertical bars. Arrows point to years of documented lag in the response of ANPP to $P_{\mathrm{T}}(\mathrm{Lag})$ and new species assemblages (NSA; from Table 3$)$. 
TABLE 3. Case studies at long-term experimental sites explaining the mechanisms driving the site-by-site, year-by-year relation between standardized iEVI and standardized total precipitation $P_{\mathrm{T}}\left(\mathrm{iEVI} \mathrm{I}_{\mathrm{S}}\right.$ and $\left.P_{\mathrm{TS}}\right)$, where the number of consecutive months with PDSI $<0$ and number of consecutive years with PDSI in September (PDSI Sep $)<20$ th percentile express the prolonged warm drought.

\begin{tabular}{|c|c|c|c|c|c|}
\hline Site & Ecosystem & $\begin{array}{c}\text { PDSI <0 } \\
\text { (consecutive months) }\end{array}$ & $\begin{array}{c}\text { PDSI }_{\text {Sep }} \\
<20 \text { th percentile } \\
\text { (consecutive years) }\end{array}$ & $\begin{array}{l}\text { Observed } \\
\text { functional response }\end{array}$ & In situ knowledge \\
\hline DER & desert & 62 & 5 & Lag, 2005 & S. G. Kitchen, field notes \\
\hline DER & desert & 97 of 124 & 8 of 10 & NSA, 2010 & S. G. Kitchen, field notes \\
\hline JRN & desert & 56 of 66 & 4 of 5 & Lag, 2004-2006 & Peters et al. (2012) \\
\hline WGE & desert & 78 of 97 & 3 of 4 & NSA, 2006-present & Scott et al. (2010) \\
\hline CPL & plains & 106 of 108 & 7 & responsive to $P_{\mathrm{TS}}$ & Evans et al. (2011) \\
\hline SPL & plains & no prolonged drought & 0 & responsive to $P_{\mathrm{TS}}$ & $\begin{array}{l}\text { S. A. Gunter, personal } \\
\text { communication }\end{array}$ \\
\hline LWA & plains & 99 of 101 & 5 & responsive to $P_{\mathrm{TS}}$ & $\begin{array}{l}\text { P. J. Starks, personal } \\
\text { communication }\end{array}$ \\
\hline
\end{tabular}

Notes: The functional responses include the lag in the response of ANPP to $P_{\mathrm{T}}$ (Lag) and new species assemblages (NSA). The in situ knowledge used to understand the mechanics of site behavior include field notes, recent publications, and personal communications. Sites listed as responsive to $P_{\text {TS }}$ are those for which no outliers exceeded $\pm 1 \sigma( \pm 1 \mathrm{SD}$; see Fig. 6$)$. See Table 1 for site names.

year ANPP was not included in the ANPP model. This may be explained by exceptions to the response trajectory associated with ecosystems that are near thresholds of change (Peters et al. 2004, Smith et al. 2009). Continuing drought in plains grasslands could eventually lead to altered ecosystem functioning similar to that reported here for desert grasslands. This is supported by findings that the persistence of water deficit largely determines the sensitivity of biomes to drought and that there are different adaptation mechanisms in arid and mesic biomes (Vicente-Serrano et al. 2013). Vicente-Serrano et al. (2013) emphasized the role of temperature in the response of vegetation to climate variability by correlating the standardized precipitation evapotranspiration index (SPEI) with vegetation activity and growth.

Together, the findings of Ponce-Campos et al. (2013) and Zhang et al. (2013) and our findings (Fig. 7) suggest that there was shift in the functional response of desert grasslands to $P_{\mathrm{T}}$. In contrast, the plains grasslands are following a predictable trajectory of ecosystem response to chronic drought that is expected to result in altered ecosystem functioning at the scale of months to decades (Smith et al. 2009). This difference in response between plains and desert grassland may be related to the adaptive responses of their dominant grass species to water availability. Plains grasslands historically and currently support large grazing populations (Briggs et al. 2005). The dominant grass assemblages of the plains grasslands maintain aboveground-belowground ratios which can impart greater capacity to physiologically adjust to climate variability, as well as facilitate community shifts, supporting greater regenerative capacity following disturbance (Knapp and Smith 2001, Zhou et al. 2009). Convergent selection pressure exerted by the combination of grazing and aridity in the plains grasslands may also be important in selecting for traits that impart substantial resistance to both disturbances (Milchunas et al. 1988, Quiroga et al. 2010). Desert grasslands, in contrast, did not coevolve with consistent grazing pressure and evolved the ability to rapidly respond to and effectively use highly variable and extremely pulsed precipitation (Bock et al. 1984, McClaran 1997). Once grass biomass is lost, grasslands can take years to recover (Peters et al. 2012), as evidenced by the lags observed for desert grasslands (Fig. 7). Such lags in grass productivity are a contributing factor to historical expansion of woody species into desert grassland systems (McClaran 2003, McClaran et al. 2010), as well as contributing to altered community structure at DER and WGE that affected ANPP precipitation responses (Fig. 6). Collectively, these observations suggest that North American grasslands will undergo predictable, but regionally distinct, responses to the prolonged warm, dry conditions which are characteristic of climate change.

Results reported here for the early 21 st century may be temporary, and the long-term impact on ecosystem functional integrity across the North American grassland biome is yet unknown. Interannual trends in plant phenology should provide a better understanding of the reported differences between arid and mesic sites, and the ecohydrological feedbacks leading to grassland mortality (Pennington and Collins 2007, Notaro et al. 2010). Also, the site-level mechanisms associated with disease and pests have not been a factor at these sites, but will likely further influence ecosystem function (Rosenzweig et al. 2001). Rising atmospheric $\mathrm{CO}_{2}$ may partially counter the effects of prolonged warm drought by increasing plant biomass (Morgan et al. 2011, Donohue et al. 2013). These variant outcomes could be attributed to the contrast between short-term experiments and studies lasting longer than a decade related to biochemical changes (Baldocchi 2011). With a longer postdrought time period, it may be possible to investigate the potential for, and dynamics of, grassland recovery and rehabilitation (e.g., Peters et al. 2012). 
Providing a prediction of the functional response of grasslands to altered hydroclimatic conditions and an operational means to monitor it has important implications. First, our work illustrates the value of experimental sites with long-term, species-scale observations of grassland dynamics combined with continuing satellitebased observations such as EVI in future studies and modeling efforts because in our case the species-specific information aided interpretation of the ANPP $-P_{\mathrm{T}}$ anomalies. Second, our results show that regional management of grassland resources related to fire risk, loss of forage, and ecosystem services can be designed to account for predictable shifts in functional processes associated with climate change. These compelling results in a natural setting at the regional scale should play a role in future grassland research, management, and policy.

\section{ACKNOWLEDGMENTS}

This study has been supported in part by NASA (08SMAPSDT08-0042), NSF (DEB-1235828), and USDA CSREES grant 2008-51130-19567. We also thank the EcoTrends Project for access to multisite, long-term data and the generous contributors to ANPP measurements, including $\mathrm{J}$. Derner (CPL) and J. Anderson (JRN).

\section{Literature Cited}

Allen, C. D., et al. 2010. A global overview of drought and heat-induced tree mortality reveals emerging climate change risks for forests. Forest Ecology and Management 259:660684.

Baldocchi, D. 2011. Global change: the grass response. Nature 476:160-161.

Biondini, M. E., W. K. Lauenroth, and O. E. Sala. 1991. Correcting estimates of net primary production: are we overestimating plant production in rangelands? Journal of Range Management 44:194-198.

Bock, C. E., J. H. Bock, W. R. Kenney, and V. M. Hawthorne. 1984. Responses of birds, rodents, and vegetation to livestock exclosure in a semidesert grassland site. Journal of Range Management 37:239-242.

Borchert, J. R. 1950. The climate of the central North American grassland. Annals of the Association of American Geographers 40:1-39.

Breshears, D. D., et al. 2005. Regional vegetation die-off in response to global-change-type drought. Proceedings of the National Academy of Sciences USA 102:15144-15148.

Briggs, J. M., and A. K. Knapp. 1995. Interannual variability in primary production in tallgrass prairie: climate, soil moisture, topographic position, and fire as determinants of aboveground biomass. American Journal of Botany 82:1024-1030.

Briggs, J. M., A. K. Knapp, J. M. Blair, J. L. Heisler, G. A. Hoch, M. S. Lett, and J. K. McCarron. 2005. An ecosystem in transition: causes and consequences of the conversion of mesic grassland to shrubland. BioScience 55:243-254.

Burnham, K. P., and D. R. Anderson. 2002. Model selection and multimodel inference - a practical information-theoretic approach. Second edition. Springer-Verlag, New York, New York, USA.

Cherwin, K., and A. Knapp. 2012. Unexpected patterns of sensitivity to drought in three semi-arid grasslands. Oecologia 169:845-852.

Collins, S. L., A. K. Knapp, J. M. Briggs, J. M. Blair, and E. M. Steinauer. 1998. Modulation of diversity by grazing and mowing in native tallgrass prairie. Science 280:745-747.
Dai, A. 2011. Characteristics and trends in various forms of the Palmer Drought Severity Index during 1900-2008. Journal of Geophysical Research 116:D12115.

Donohue, R. J., M. L. Roderick, T. R. McVicar, and G. D. Farquhar. 2013. Impact of $\mathrm{CO}_{2}$ fertilization on maximum foliage cover across the globe's warm, arid environments. Geophysical Research Letters 40:3031-3035.

Easterling, D. R., G. A. Meehl, C. Parmesan, S. A. Changnon, T. R. Karl, and L. O. Mearns. 2000. Climate extremes: observations, modeling, and impacts. Science 289:2068-2074.

Epstein, H. E., R. A. Gill, J. M. Paruelo, W. K. Lauenroth, G. J. Jia, and I. C. Burke. 2002. The relative abundance of three plant functional types in temperate grasslands and shrublands of North and South America: effects of projected climate change. Journal of Biogeography 29:875-888.

Evans, S. E., K. M. Byrne, W. K. Lauenroth, and I. C. Burke. 2011. Defining the limit to resistance in a drought-tolerant grassland: long-term severe drought significantly reduces the dominant species and increases ruderals. Journal of Ecology 99:1500-1507.

Frich, P., L. V. Alexander, P. DellaMarta, B. Gleason, M. Haylock, A. M. G. K. Tank, and T. Peterson. 2002. Observed coherent changes in climatic extremes during the second half of the twentieth century. Climate Research 19:193-212.

Heisler-White, J. L., J. M. Blair, E. F. Kelly, K. Harmoney, and A. K. Knapp. 2009. Contingent productivity responses to more extreme rainfall regimes across a grassland biome. Global Change Biology 15:2894-2904.

Huete, A., K. Didan, T. Miura, E. P. Rodriguez, X. Gao, and L. G. Ferreira. 2002. Overview of the radiometric and biophysical performance of the MODIS vegetation indices. Remote Sensing of Environment 83:195-213.

Huxman, T. E., et al. 2004. Convergence across biomes to a common rain-use efficiency. Nature 429:651-654.

Jönsson, P., and L. Eklundh. 2004. TIMESAT - a program for analyzing time-series of satellite sensor data. Computers and Geosciences 30:833-845.

Knapp, A. K., and M. D. Smith. 2001. Variation among biomes in temporal dynamics of aboveground primary production. Science 291:481-484.

Lauenroth, W. K., and O. E. Sala. 1992. Long-term forage production of North American shortgrass steppe. Ecological Applications 2:397-403.

Lyman, R. L., and S. Wolverton. 2002. The late prehistoricearly historic game sink in the northwestern United States. Conservation Biology 16:73-85.

MacDonald, G. M. 2010. Water, climate change, and sustainability in the southwest. Proceedings of the National Academy of Sciences USA 107:21256-21262.

McAfee, S. A., and J. L. Russell. 2008. Northern Annular Mode impact on spring climate in the western United States. Geophysical Research Letters 35:L17701.

McAuliffe, J. R., and E. P. Hamerlynck. 2010. Perennial plant mortality in the Sonoran and Mojave deserts in response to severe, multi-year drought. Journal of Arid Environments 74: 885-896.

McCarron, J. K., and A. K. Knapp. 2001. C 3 woody plant expansion in a $\mathrm{C}_{4}$ grassland: are grasses and shrubs functionally distinct? American Journal of Botany 88:18181823.

McClaran, M. P. 1997. Desert grasslands and grasses. Pages 130 in M. P. McClaran and T. R. V. Devender, editors. The desert grassland. University of Arizona Press, Tuscon, Arizona, USA.

McClaran, M. P. 2003. A century of vegetation change on the Santa Rita Experimental Range. Pages 16-33 in M. P. McClaran, P. F. Ffolliott, and C. B. Edminster, editors. Santa Rita Experimental Range: 100 years (1903 to 2003) of accomplishments and contributions. Conference proceedings, Tucson, Arizona, October 30-November 1, 2003. USDA, 
Forest Service, Rocky Mountain Research Station, Fort Collins, Colorado, USA.

McClaran, M. P., D. M. Browning, and C. Huang. 2010. Temporal dynamics and spatial variability in desert grassland vegetation. Pages 145-166 in R. H. Webb, D. E. Boyer, and R. M. Turner, editors. Repeat photography: methods and applications in the natural sciences. Island Press, Washington, D.C., USA.

McPherson, G. R. 1997. The role of fire in the desert grassland. Pages 130-151 in M. P. McClaran and T. R. V. Devender, editors. The desert grassland. University of Arizona Press, Tuscon, Arizona, USA.

Milchunas, D. G., O. E. Sala, and W. K. Lauenroth. 1988. A generalized model of the effects of grazing by large herbivores on grassland community structure. American Naturalist 132: 87-106.

Morgan, J. A., D. R. LeCain, E. Pendall, D. M. Blumenthal, B. A. Kimball, Y. Carrillo, D. G. Williams, J. Heisler-White, F. A. Dijkstra, and M. West. 2011. $\mathrm{C}_{4}$ grasses prosper as carbon dioxide eliminates desiccation in warmed semi-arid grassland. Nature 476:202-205.

Muldavin, E. H., D. I. Moore, S. L. Collins, K. R. Wetherill, and D. C. Lightfoot. 2008. Aboveground net primary production dynamics in a northern Chihuahuan Desert ecosystem. Oecologia 155:123-132.

Notaro, M., Z. Liu, R. G. Gallimore, J. W. Williams, D. S. Gutzler, and S. Collins. 2010. Complex seasonal cycle of ecohydrology in the Southwest United States. Journal of Geophysical Research-Biogeosciences 115:G04034.

Peltzer, D. A., and M. Köchy. 2001. Competitive effects of grasses and woody plants in mixed-grass prairie. Journal of Ecology 89:519-527.

Pennington, D. D., and S. L. Collins. 2007. Response of an aridland ecosystem to interannual climate variability and prolonged drought. Landscape Ecology 22:897-910.

Peters, D. P. C., R. A. Pielke, B. T. Bestelmeyer, C. D. Allen, S. Munson-McGee, and K. M. Havstad. 2004. Cross-scale interactions, nonlinearities, and forecasting catastrophic events. Proceedings of the National Academy of Sciences USA 101:15130-15135.

Peters, D. P. C., J. Yao, O. E. Sala, and J. P. Anderson. 2012. Directional climate change and potential reversal of desertification in arid and semiarid ecosystems. Global Change Biology 18:151-163.

Ponce-Campos, G. E., et al. 2013. Ecosystem resilience despite large-scale altered hydroclimatic conditions. Nature 494:349352.

Quiroga, R. E., R. A. Golluscio, L. J. Blanco, and R. J. Fernández. 2010. Aridity and grazing as convergent selective forces: an experiment with an Arid Chaco bunchgrass. Ecological Applications 20:1876-1889.

Reichmann, L. G., O. E. Sala, and D. P. C. Peters. 2013. Precipitation legacies in desert-grassland primary production occur through previous-year tiller density. Ecology 94:435443.

Rosenzweig, C., A. Iglesius, X. B. Yang, P. Epstein, and E. Chivian. 2001. Climate change and extreme weather events- implications for food production, plant diseases, and pests. Global Change and Human Health 2(2):90-104.

Sala, O. E., M. E. Biondini, and W. K. Lauenroth. 1988a. Bias in estimates of primary production: an analytical solution. Ecological Modelling 44:43-55.

Sala, O. E., et al. 2000. Global biodiversity scenarios for the year 2100. Science 287:1770-1774.

Sala, O. E., L. A. Gherardi, L. Reichmann, E. Jobbágy, and D. Peters. 2012. Legacies of precipitation fluctuations on primary production: theory and data synthesis. Philosophical Transactions of the Royal Society B 367:3135-3144.

Sala, O. E., W. J. Parton, L. A. Joyce, and W. K. Lauenroth. $1988 \mathrm{~b}$. Primary production of the central grassland region of the United States. Ecology 69:40-45.

Scott, R. L., E. P. Hamerlynck, G. D. Jenerette, M. S. Moran, and G. A. Barron-Gafford. 2010. Carbon dioxide exchange in a semidesert grassland through drought-induced vegetation change. Journal of Geophysical Research 115:G03026.

Seager, R., et al. 2007. Model projections of an imminent transition to a more arid climate in Southwestern North America. Science 316:1181-1184.

Sheppard, P. R., A. C. Comrie, G. D. Packin, K. Angersbach, and M. K. Hughes. 2002. The climate of the US Southwest. Climate Research 21:219-238.

Smith, M. D., A. K. Knapp, and S. L. Collins. 2009. A framework for assessing ecosystem dynamics in response to chronic resource alterations induced by global change. Ecology 90:3279-3289.

Solomon, S., D. Qin, M. Manning, Z. Chen, M. Marquis, K. Averyt, M. Tignor, and H. Miller. 2007. Climate change 2007: the physical science basis. Contribution of Working Group I to the fourth assessment report of the Intergovernmental Panel on Climate Change. Cambridge University Press, New York, New York, USA.

Suttle, K. B., M. A. Thomsen, and M. E. Power. 2007. Species interactions reverse grassland responses to changing climate. Science 315:640-642.

Vicente-Serrano, S. M., et al. 2013. Response of vegetation to drought time-scales across global land biomes. Proceedings of the National Academy of Sciences USA 110:52-57.

Weiss, J. L., C. L. Castro, and J. T. Overpeck. 2009. Distinguishing pronounced droughts in the Southwestern United States: seasonality and effects of warmer temperatures. Journal of Climate 22:5918-5932.

Williams, J. W., and S. T. Jackson. 2007. Novel climates, noanalog communities, and ecological surprises. Frontiers in Ecology and the Environment 5:475-482.

Willis, K. J., and S. A. Bhagwat. 2009. Biodiversity and climate change. Science 326:806-807.

Zhang, Y., et al. 2013. Extreme precipitation patterns and reductions of terrestrial ecosystem production across biomes. Journal of Geophysical Research-Biogeosciences 118:148157.

Zhou, X., M. Talley, and Y. Luo. 2009. Biomass, litter, and soil respiration along a precipitation gradient in southern Great Plains, USA. Ecosystems 12:1369-1380. 